\title{
Producción social de cuerpos, divisiones sociales y marginación en el desarrollo urbano de la ciudad de Bogotá
}

\author{
Éder Alexánder García Dussán \\ Universidad Distrital Francisco José de Caldas, Bogotá, Colombia \\ eagarciad@udistrital.edu.co \\ https://orcid.org/0000-0002-6635-2725
}

\section{RESUMEN}

Desde el siglo XIX, la ciudad de Bogotá se ha caracterizado por el auge de una sensibilidad moderna promovida por una educación estética (aisthesis). Esta función educadora, adelantada por un grupo de letrados, permitió coconstruir y perpetuar sujetos diferentes y desiguales y, por tanto, una marginalidad con disímiles estilos de vida. Fue así como la ciudad se dividió en un pueblo ordinario y violento que se opuso al de gente de buen gusto, de buen tacto, de las buenas formas y del hablar con buen tono; que es la misma dicotomía entre gente sensible e insensible. A partir de esto,

nos proponemos analizar algunos efectos de esta formación corporal, centrando el esfuerzo en la controversia suscitada cuando, en 1982, el mundo conoció que Gabriel García Márquez había ganado el Nobel de Literatura. Esto nos permite concluir que perdura una división de sujetos sociales anclada como base de la epistemología social que puede ser interpretada desde los conceptos de violencia epistémica o complejo de ilegitimidad.

Palabras-clave: ciudad; hiperestesias; modernismo; corporalidad; marginación.

Cómo citar: García, E. (2020). Producción social de cuerpos, divisiones sociales y marginación. Ciencias Sociales y Educación, 9(18), 137-157. https://doi.org/10.22395/csye.v9n18a6

Recibido: 12 de febrero de 2020.

Aprobado: 10 de julio de 2020. 


\section{Social Production of Bodies, Social Division and Marginalization in the Urban Development of Bogota City}

\section{ABSTRACT}

Since the XIXth century, Bogota City has characterized for the boom of a modern sensibility promoted by an aesthetic education (aisthesis). This educational function, carried out by a group of literates allowed the co-construction and perpetuation of different and unequal subjects, and thus, a marginality with dissimilar ways of life. That is how the city was divided into a ordinary and violent town that was opposed to fine taste people, with touch, well mannered and with a correct speech tone; which is the same dichotomy than between sensitive and insensitive people. Taking this into account, the research purpose is to analyze some of the effects of this corporeal formation, centering efforts in the controversy raised when, in 1982, the world knew how Gabriel García Márquez was awarded the Nobel Prize in Literature. This allows the research to conclude that there still is a division of social subjects anchored as a social epistemological base that could be interpreted from the concepts of epistemic violence or illegitimacy complex.

Keywords: city; hyperesthesias; modernism; corporeality; marginalization.

\section{Produção social de corpos, divisões sociais e marginalização no desenvolvimento urbano da ciddade de Bogotá}

\section{RESUMO}

Desde o século XIX, a cidade de Bogotá tem se caracterizado pelo surgimento de uma sensibilidade moderna promovida por uma educação estética (aisthesis). Esta função educativa, desempenhada por um grupo de letrados, permitiu coconstruir e perpetuar sujeitos diferentes e desiguais e, portanto, uma marginalidade com estilos de vida díspares. Foi assim que a cidade se dividiu em um povo comum e violento, que se opôs ao de bom gosto, bom tato, boas maneiras e bom tom; que é a mesma dicotomia entre pessoas sensíveis e insensíveis. A partir disso, propomos analisar alguns efeitos dessa formação corporal, focalizando nossos esforços na polêmica que surgiu quando, em 1982, o mundo soube que Gabriel García Márquez havia ganhado o Prêmio Nobel de Literatura. Isso nos permite concluir que uma divisão dos sujeitos sociais permanece ancorada como base da epistemologia social que pode ser interpretada a partir dos conceitos de violência epistêmica ou complexo de ilegitimidade.

Palavras-chave: cidade; corporalidade; hiperestesia; marginalização; modernismo. 


\section{Introducción}

Si partimos de una lectura profunda de las obras del historiador argentino José Luis Romero (1974) y el crítico uruguayo Ángel Rama (1984) sobre la formación de las ciudades latinoamericanas, entrevemos que su devenir se ha cifrado en términos del cuidado de una tensión social excluyente que consiste en la confrontación de dos grupos sociales antagónicos bajo la lógica inicial de colonizador-nativo y que evolucionó en encomenderos-aborígenes, nobleza-indios, criollos-mestizos, patronos-siervos, élite burguesa-clase popular, etc. Esta acción se sostuvo gracias al poder escriturario de una capa social concreta, la de intelectuales de densa burocracia y alta jerarquía (los letrados), quienes han venido ordenado, desde el centro de las ciudades, los signos para exaltar la santidad de los cuerpos urbanos y sostener en la escritura y en la realidad la ciudad ideal o la Jerusalén celestial, imaginada por los reyes españoles en la nueva América.

En el caso de la ciudad de Bogotá, desde el comienzo de su historia colonial con la inauguración de la Plaza Mayor, ceñida entre los ríos San Francisco y San Agustín, permitió que ese foco urbano fuera un lugar sagrado, mientras que fuera de esos límites acuosos aparecieron los lugares diabólicos y profanos donde se reunía el pueblo, reducidos al encuentro de lavanderas, aguaderos, mulatos e indios. De esta manera, lo lejano a la Plaza fue el lugar de reunión de los villanos, asociados desde entonces al gentío que ocupaba el lugar de borde, tiránicamente asociado con el lugar-del-mal (Aprile-Gniset, 1991).

Así las cosas, se estableció una analogía ideal: ciudad-centro-sagradoblancos/pueblo-periferia-profano-indios que solo se quebrantó por el principio de realidad. Por una parte, el agua para cocinar salía del lugar profano. Por otra parte, la fuerza peona para la construcción de casas, iglesias, conventos, edificios administrativos y los puentes sobre los ríos San Agustín y San Francisco, sumado a la realización de actividades domésticas (cocina, huertas, aseo general, conducción del agua, etc.), invadía azarosamente el lugar céntrico y sagrado.

Esta necesidad del trabajador para el amo hizo que en 1590 y hasta 1741, se creara la mita urbana, un sistema legal que reguló la contratación individual de indígenas y su paga. La solicitud de mano de obra así regulada generó una migración forzosa de indígenas. Se estima que en el último cuarto del siglo XVI ingresaban a Santafé de ochocientos a mil trabajadores indígenas mensualmente, aunque ese número era insuficiente para las necesidades de la ciudad. Claramente, este hecho no solo multiplicó por cuatro la población, sino que comenzaron los problemas de alojamiento para estas brigadas, apareciendo así insípidos asentamientos informales o barriadas. 
Ahora bien, al seguir pistas de esta forma de comprender la topo-sintaxis céntrico-periférica de la Bogotá colonial, y bajo la estricta lógica espacial del rectángulo (damero), en las manzanas más cercanas a la Plaza Mayor se instalaron los vecinos más acaudalados y nobles, lo que significó que a lo lejos se ubicarían los sujetos menos prestantes por tener menos recursos, aunque sí más placer y libertinaje. En otros términos, se especializó una topofobia a lo marginal y, en términos sociales, una segregación que clasificó cuerpos y, claramente, también corporalidades en la ciudad capital de Colombia. Esto dio origen a los barrios ocupados por minorías étnicas. Las plazas menores de San Francisco y San Agustín eran lugares para 'la plebe' (Páramo, 2002).

Esta cualidad social se prolongó así durante siglos hasta que, a partir de 1880, en la "ciudad burguesa", término prestado de la obra José Luis Romero (1974), se comenzó a experimentar una cantidad de cambios en su gramática social y urbana, debido especialmente al progresivo fenómeno de migración que abría posibilidades de empleo. El político Higinio Cualla García, alcalde de Bogotá desde 1884 hasta 1900, materializó el proyecto burgués de borrar las huellas coloniales de la ciudad con la inauguración del tranvía de mulas y los ferrocarriles del occidente de la ciudad, además del embellecimiento de los parques y calles, la instalación de un acueducto con tubería de hierro y del teléfono, la edificación de hospitales, la canalización de ríos, la construcción de puentes, la aparición de cafés, hoteles y restaurantes, entre otros beneficios materiales, evidentes desde 1885.

No obstante, la ciudad mantuvo esa marginación entre burgueses y plebes. Así, impidió para los primeros "las limitaciones de los gustos y la falta de comodidades que la época prometía brindar a quienes tuvieran los medios para cogerlos" (Mejía, 2011, p. 19), lo cual se reforzó con la vigilancia policial que se ejerció desde finales del siglo XIX y comienzos del XX sobre los lugares de evidente uso y gusto burgueses. Esto quiere decir que la ciudad seguía manteniendo una división tajante a propósito de sus capas sociales constitutivas. Esto se hizo manifiesto en la Bogotá republicana por la tirantez entre, por un lado, los cachacos o aristócratas adinerados y sus engreídos hijos, los pepitos, visibles por sus acciones de divertimento y por sus excesos de lujo ${ }^{1} ;$ y, por otro lado, los guaches o el común de los moradores de la ciudad, esto es, la gente de a pie o los pobres, caracterizados por estar "hacinados en las nefastas tiendas de habitación, sólo consiguieron que para ellos se comenzara a pedir insistentemente la construcción de 'barrios obreros' en las afueras de la ciudad" (Mejía, 2011, p. 21).

En la década de 1950 los pepitos también fueron llamados "los hijos de papi" o "coca-colos", bogotanismo en desuso "con el cual los adultos tradicionales designaron a los jóvenes que absorbían la modernidad" (Ortiz, 2012, p. 108). Era un grupo de jóvenes buscapleitos e irreverentes que asistían a discotecas light, amantes de tomar la bebida Cocacola, de usar blue jean, gafas oscuras y chaquetas de cuero.. 
De esta suerte, esta característica — propia de la ciudad desde la Colonia y acentuada en la época decimonónica con ecos hasta los siglos XX y XXI-marca el derrotero de una producción de representaciones corporales y, por tanto, de una corporalidad, esto es, de un conjunto de representaciones sobre la tenencia de un cuerpo según el lugar social que ocupa en la ciudad y su respectiva concienciación de ese cuerpo como elemento clave para generar marginación y discriminación de sujetos (Pedraza, 2004a).

Para el caso de Bogotá, estas corporalidades inician en la dicotomía castas españolas y castas de tierra. En este contexto, la representación del cuerpo se constituía gracias a la demostración de una esencia de nobleza determinada por la cercanía a la descendencia española que termina en una división de razas, blanco y negro. Esta división se centra en una visión de cuerpo orgánico que, según su raza, revela determinadas especificidades morales e intelectuales (Pedraza, 2004b) ${ }^{2}$ y que, en la actualidad, se juega en estratagemas estéticopolíticas que fluctúan ora en el blanqueamiento, ora en el negriamiento del soma, pero guiadas bajo las lógicas de la resistencia y la transformación de la figura corporal. Es así como los habitantes de la ciudad de Bogotá han sido distinguidos, clasificados y excluidos según sus cualidades raciales y según dichas oposiciones. Con la consecuente constitución de su corporalidad diferenciadora, se creó una nueva percepción de la organización social "alrededor de la ilusión de una filiación con modos y costumbres de países vistas como civilizados, que sirvió de legitimación a sistemas [...] de clasificación de las personas, que, sin embargo, siguieron siendo las mismas castas raciales coloniales" (Lozano, 2001, p. 86).

Pues bien, a partir de este panorama, nuestro interés en esta reflexión es describir y explicar cómo esta división social y su desigualdad constitutiva evolucionó en la ciudad de Bogotá hasta madurar en una nueva dicotomía excluyente, la de cachacos y corronchos (bogotanos/andinos y costeños) como nuevo rostro de la de burgués y plebeyo. Todo esto se hizo con el fin de ver hasta dónde este hecho tan particular ha prolongado una identidad social y la formación de unas nuevas subjetividades, lo cual nos ayuda a comprender quiénes somos justamente cuando se revela lo que hemos sido al arrastrar un hecho que sirvió de partero de las ciudades: la tensión excluyente de cuerpos y la consecuente marginalidad de aquellos que no comparten rasgos esenciales ni aparentes con la nobleza.

Para avanzar en este propósito, lo primero que desplegaremos es una deliberación que teja una red de conceptos básicos que nos permitan describir cómo se formaron las representaciones de los cuerpos en castas sociales para dar

Acuñamos en esta reflexión la noción de raza como una categoría popular y una noción práctica que refiere a un conjunto de características físicas de una persona o un colectivo y que se asocian directamente con cualidades intelectuales y espirituales (Pedraza, 2008). 
cuenta, en un segundo momento y con base en este modelo interpretativo, de esa nueva forma excluyente de clasificación y partición corporalizada en la capital de Colombia en el siglo XX. Esta ciudad encasilla, por un lado, la paridad lobos y corronchos como contenidos propios de la exclusión corroncho-cachaco, y dentro de este último conjunto, la tríada rolos, bogotanos y bogoteños. Finalmente analizaremos, como ejemplo concreto de la supervivencia de esta forma de exclusión simbólica y real, la controversia que se suscitó en el país debido a la elección del equipo humano de colombianos que acompañaron al escritor Gabriel García Márquez a recibir el Premio Nobel de Literatura a comienzos de diciembre de 1982 en la Sala de Conciertos de Estocolmo (Suecia), lo cual fue interpretado por algunas capas sociales céntricas como una corronchada. Todo esto, anudado, nos permitirá hacer conclusiones en términos de los rasgos característicos que definen una posible traza de la identidad social colombiana o colombianía, en la cual se esbozan rasgos de violencia epistémica.

\section{Premisas teóricas y antecedentes de la producción de corporalidades en la ciudad de Bogotá}

Si nos preguntamos por las condiciones sociohistóricas que han permitido la evolución de las formas de representación del cuerpo humano en nuestros cuerpos urbanos latinoamericanos, tendríamos que responder que estas circunstancias y realidades están construidas sobre un conjunto de hiperestesias. Estas se entienden como el estado ampliado de las producciones sensibles que se generan e instalan en la cognición de un colectivo de sujetos determinado históricamente gracias al trabajo de un ordenamiento de las percepciones sensoriales de/en los sujetos, y que luego son usadas para construir juicios estéticos (Pedraza, 1999).

Para el caso que nos interesa, desde el siglo XIX la ciudad burguesa bogotana (1880-1910, aproximadamente) se caracterizó por el cultivo progresivo de una sensibilidad moderna, entendida como el agregado solidario de, por una parte, un conjunto de prácticas que auxiliaban los cuidados corporales creados por una consciencia sensible, como sucede en el discurso caligénico (sensorialidades); $y$, por otra, por el perfeccionamiento de las percepciones sensoriales a través de una educación de los sentidos o educación estética que procuraba un aprendizaje de las sensaciones olfativas, gustativas, cromáticas, auditivas, así como de las emociones básicas como el miedo, la ira o el asco hacia lo otro y el otro (sensitividades). Ahora bien, esta sensibilidad específica, suma aritmética de las sensorialidades y las sensitividades en la que se especializaban unos cuantos moradores de las ciudades decimonónicas, se manifestaba en la población privilegiada a través de un conjunto de rasgos característicos de la élite burguesa: un correlato poético adaptado a las circunstancias locales que fungía como folleto de las actitudes burguesas epocales; la ejecución de una educación de los sentidos que perfilaba otros cuerpos y sus corporalidades; la 
afirmación de un individualismo; y, finalmente, el privilegio de un ámbito de intimidad como espacio y condición humana de cotidianidad ${ }^{3}$. Pues bien, en lo que sigue desarrollaremos brevemente detalles de cada uno de estos elementos constitutivos de las nuevas sensibilidades instaladas en la ciudad de Bogotá durante el siglo XIX.

Para comenzar este breviario de detalles, es importante recordar que aquel movimiento letrado que anudó a Rubén Darío, Lugones, Martí y otros, esto es, el Modernismo, sale a la luz a través de una poesía que revalora la instrumentación sensitiva jalonada por una producción literaria que desea huir de la realidad sociopolítica marcada por guerras civiles, subdesarrollo y crisis urbana en términos de urbanización. Por esta razón, se caracterizó por enunciar un ideal aristocrático mezclado con un romanticismo, lo que permitió expresar una cosmovisión hermética y una condición nómada de morar las urbes, manifestada en temas poéticos como la infancia perdida y la soledad. Estos mecanismos semánticos les permitieron incluirse a sí mismos e incluir a sus iguales en los entendimientos de la sociedad burguesa o, lo que es igual, se soslayaron los problemas sociales y se sustituyeron por lo privado. Con esta estratagema se permitió comunicar "lo subjetivo, lo espiritual, lo secreto, lo reservado, lo profundo, lo fraternal y lo doméstico, que, para los burgueses de entonces, eran lo propio de esa faceta de la existencia humana" (Mejía, 2011, p. 34).

Esta apuesta también se revelaba en acciones más mundanas, como la fundación y establecimiento de sus vidas familiares en nuevas zonas residenciales que evitaran vivir sin mezclarse con el pueblo (Chapinero fue ese lugar en el caso de la ciudad de Bogotá) y en la amplitud y el lujo del interior de sus casaquintas o mansiones, equipadas con enseres europeos. Todo esto terminó por diferenciarlos totalmente del orbe de sujetos desfavorecidos socioeconómicamente que vivían con lo más básico y en condición de hacinamiento y abigarramiento. De esta manera, se enquistó en la fisiología urbana lo que Mejía (2011) llama la "segregación espacial" (p. 41) como correlato de la marginalidad social en ese funcionamiento social. En este contexto, comenta el filósofo y ensayista colombiano Rafael Gutiérrez (1987):

A mediados de 1850 en Santafé y Bogotá se hacían tertulias, imitando a las de París y Londres; ello implicó el cambio del mueblaje por el estilo del primer imperio francés acompañados de espejos de cuerpo entero y marco color oro, porcelanas, alfombras, pianos y relojes de sobremesa con figuras de bronce; y en el comedor se cambiaron los trinches de hierro por tenedores de metal blanco [...]. El eclectismo arquitectónico y el cosmopolitismo de intérieur enriquecieron la expresión cotidiana y, con ello, el enriquecimiento de la expresión poética de Silva, por ejemplo. (pp. 83-84)

Afirmamos que los cuatro rasgos manifiestos en la burguesía hacían parte de su carácter o temperamento. Se comprende este concepto como aquellas características propias de un sujeto o grupo de ellos en relación con la forma en que se expresan en ciertas situaciones frente al otro y a lo otro. 
Asimismo, la élite burguesa se imbuía y ensimismaba en su mónada social gracias al desarrollo de una educación estética liderada por un grupo de letrados concretos, a saber, los pedagogos sociales y los filólogos eruditos, quienes se encargaron de coconstruir, con su labor, sujetos desiguales bajo criterios protocolarios y lingüísticos. Con estas divisiones sociales así establecidas, estimulaban disímiles estilos de vida entre los habitantes de las ciudades, en la que los sentidos se reeducaron bajo una lógica contrapuesta a la de los plebeyos, quienes se quedaban representados como pequeños bárbaros. En este sentido, obras como Apuntaciones críticas sobre el lenguaje bogotano", publicada entre 1867-1872 por el bogotano Rufino José Cuervo Urrisarri, se convierte en un best seller de la época por identificar a sus lectores con exclusividad y distinción. En este libro, Cuervo (2012) explica a los burgueses el correcto uso del habla, desde los niveles fonético hasta el léxico-semántico, sin descuidar fenómenos morfosintácticos. Asimismo sucede con el Manual de urbanidad y buenas maneras, redactado por el venezolano Manuel Antonio Carreño y publicado en 1853. En esta obra, Carreño (2000) trazó la noble misión de enseñar conductas, tales como la correcta forma de asearse, vestirse, caminar en la calle, hablar en público, etc. Esto quiere decir que la élite letrada decimonónica en Bogotá tuvo la tarea de enseñar urbanidad, higiene, corrección idiomática, economía doméstica, entre otros, al interior de las mansiones; todo esto codificado en manuales y folletos hogareños ${ }^{4}$.

Esta sensibilidad moderna bogotana, propia de los favorecidos, estuvo marcada por la conservación de ideales heredados del orden señorial de las ciudades hidalga, criolla y patricia, donde "su sentido de democracia consistía en un proceso de selección espiritual que se basaba en una cultura selecta, adquirida justamente por obra del hiperestesiamiento" (Pedraza, 1999, p. 44). Aún más, podemos cotejar esa cultura selecta con lo que el filósofo alemán Herbert Marcuse (1978) llamó en 1967 la cultura afirmativa o platonismo aburguesado, cuya característica fundamental

es la afirmación de un mundo valioso [...] que ha de ser reforzado incondicionalmente y que es eternamente superior, esencialmente diferente del mundo real de la lucha cotidiana por la existencia, pero que todo sujeto [...] puede realizar por sí mismo. Sólo [sic] aquí las actividades y objetos culturales obtienen aquella dignidad que los eleva por encima de lo cotidiano; y así el destino del hombre, a quien le está negada la satisfacción en el mundo material, queda ubicado como ideal. (pp. 50-51)

Así las cosas, las actividades culturales como ir al teatro, el hipódromo, la ópera o a la plaza de toros - todos escenarios que imitaban estilos foráneosy practicar deportes de típica marca burguesa, señalan la especificidad de

Así, por caso, en la obra de Carreño (2000) se pueden encontrar las normas del aseo personal y de la conversación según el género, así como los modos de conducirse dentro y fuera de la casa, por ejemplo, en una visita, en una reunión, etc. 
una cultura selecta que los separaba del pueblo, es decir, de todo aquello que denotaba desorden, desaseo, comidas y bebidas autóctonas, malos olores y, por tanto, incomodidad, aversión y mal gusto. No gratuitamente, hasta 1895 el alcalde de turno en Bogotá, Cualla García, impone la construcción de letrinas en todas las viviendas de la ciudad a la vez que se intensifica el descontento por el exceso de chicherías, esto es, tiendas de poca monta donde se vendían bebidas de tradición indígena a base maíz fermentado, lo cual era neutralizado con la motivación del consumo de la cerveza como conducta propia del gusto burgués (Amaya, 2016).

A esto se sumó la conducta de comenzar a comer fuera de casa en restaurantes que brindaba comidas no autóctonas, invento urbano nacido en París hacia 1765 por Boulanger, y que funcionaba como albergue donde se ofrecía comida. Desde su nacimiento, como otro producto más del Siglo de las Luces, esto significaba posada que prometía comida para restaurarse de los ajetreos que genera vivir y circular en la ciudad (Gaitán, 2005, p. 316).

Siguiendo con la revisión de las consecuencias de esa educada sensibilidad hiperestésica de la capa burguesa en las ciudades latinoamericanas, tenemos el elemento del individualismo exagerado que supone una vuelta de los sentimientos propios que alimentan un egoísmo de rebote, una indiferencia que los obliga a menguar "la interacción en la esfera pública, sumada al refinamiento estético" (Pedraza, 1999, p. 45). Esta tendencia es común en poetas como José Asunción Silva, Guillermo Valencia, Eduardo Castillo o Baldomero Sanín Cano. En el caso colombiano, estos poetas sedimentaron una nueva sensibilidad manifestada en sus productos artísticos basados en una arrogancia cierta cuando, con el uso del lenguaje plástico, deseaban huir del tiempo (a través de la evocación del pasado), del espacio (poemas cuyo topos son lugares fantásticos, exóticos y distantes) y de la crisis social (búsqueda de la belleza a través de la elegancia verbal). Esa exploración por encontrar la belleza y la utopía con el lenguaje poético se alcanza con el uso de la aliteración y la sinestesia que construyen sus poemas al mezclar sensaciones de distintos órganos de los sentidos, así como el intimismo del poeta que hace uso de su cenestesia o interiocepción ${ }^{5}$.

La sinestesia y la cenestesia aplicada por estos poetas los llevó, entonces, y gracias al orden que produce el poder de la letra, a manifestar un modo de

\footnotetext{
Entendemos por cenestesia o interiocepción la comunicación de sensaciones experimentadas por el artista con respecto a su propio cuerpo personal. Estas sensaciones fluctúan en un cuerpo urbano reducido simbólicamente por efectos de la separación material y social que los cualifica. Para lograr esto, usa algunas figuras retóricas privilegiadas como la aliteración y la sinestesia. La primera es una figura fónico-gráfica y lexical de palabras dispuestas linealmente que consiste en la repetición del mismo sonido en distintas palabras, mientras que la segunda es una figura de sentido que producen figuraciones y consiste en una combinación de sensaciones (auditivas, visuales, táctiles, etc.) con sentimientos. Su etimología, syn-aesthesis, es clave para nosotros (Calsamiglia y Tusón, 2002).
} 
vida: justo un individualismo que los estimulaba a participar entre ellos y a incomunicarse con la masa. Este hecho los obligaba a apartarse con su familia y sus amigos a la periferia. No eran sujetos destronados, sino excluyentes, lo que permitía que la multitud popular se mantuviera en los bordes físicos y sociales . Así, pues, los burgueses replegados a la vida doméstica vigorizaron esa notoria ausencia de solidaridad, en suma, de una ética ciudadana y de una conciencia de lo público como hecho del común y de un destino común (Jaramillo, 1998; Béjar, 1998).

De hecho, esto ya había sido reflexionado por el sociólogo alemán George Simmel (1986), quien escribe que el individualismo, propio del Modernismo, está fundamentado en la intensificación de la vida nerviosa. Este es un efecto directo del cambio sensoperceptivo que las ciudades modernizadas y progresivamente masificadas generan en sus moradores, quienes tienen que experimentar acciones nuevas, como caminar por las calles y adaptarse a una nueva vida profesional, que difieren del lento vivir del campo y del pueblo. En este sentido, podemos entender, en primer lugar, cómo en Europa, Charles Baudelaire (2003) crea el poema en prosa: una lírica hipersensible y altamente emotiva, sin ritmo y sin rima. Esta lírica está ávida de sobresaltos, tal como la ciudad moderna obliga a vivir a sus habitantes. En segundo lugar, podemos comprender cómo en Bogotá, José Asunción Silva escribe De sobremesa (1993), unos de sus poemas más emblemáticos. En esta obra, el protagonista José Fernández se mueve al interior de salones y de moradas privadas, reflejo de la interiocepción del protagonista quien, en rol de dramatis personae, lee su diario y deja ver su interioridad.

Finalmente, la gran secuela de todo lo anterior es que la capa social burguesa en las ciudades, y Bogotá no fue la excepción, se muestra apática y temerosa a los espacios púbicos urbanos, lo cual la lleva a construir una zona propia. Así, se origina la esfera privada de la época, la cual se caracteriza por una intensidad vital que se sostiene bajo la lógica del familismo como la clave más importante de ese universo íntimo. Justamente por esta actitud y sus efectos, la socióloga española Helena Béjar (1998) afirma que

[1]a familia es el ámbito de la autenticidad en el marco de unas relaciones templadas al calor de la intimidad. La democracia atomiza el espacio público y debilita el sentido de la ciudadanía, pero estrecha lazos naturales y de parentesco. Algo había tener de positivo el individualismo. (p. 84)

Esta vida privada e intimidad, en el caso de la burguesía colombiana, "no contenía un ámbito para la expresión corporal, la intimidad y la expresión de la subjetividad que paliara las exigencias impuestas en los ámbitos públicos y productivo [sino que] esa intimidad se convierte en el fundamento mismo de la constricción personal" (Pedraza 2011, p. 120). Esto hacía, entonces, que la 
vida privada de la burguesía bogotana empatara con la vida señorial, basada en fuertes principios hispano-católicos.

Es así como parte de la ciudad letrada de los siglos XIX y XX, con la reproducción de esas hiperestesias - y sus consecuentes juicios estéticos-, se propuso como meta y modelo de la subjetividad moderna un yo individual inteligente, sobrio, tonificado, vigoroso e íntimo que, no obstante, camina por la ciudad. Esta se vuelve cada vez más modernizada, pero se repliega en un individualismo que origina la esfera privada donde los cuerpos se rehacen en función del buen tono y el buen gusto, impidiendo "[...] el ascenso de grupos que amenazaran su legitimidad y superioridad" (Pedraza, 2011, p. 120). He ahí las causas y los alcances de tan evidente marginalidad social de los cuerpos, de los cautivos en la plebe bogotana.

Todos estos patrones sociales creaban la homogeneidad del burgués. No reproducirlos, implicaba exclusión y, posteriormente, desigualdad y marginalización. Hay, así, una estética de lo bello agenciada por esa cultura selecta que, con la llegada del siglo XX, crea una nueva capa social: la del pueblo ordinario y violento. Se trata del mundo de los corronchos, montañeros, ñeros, desechables o lobos. Este mundo social se opone al de la gente de buen gusto, buen tacto, buenas formas y del hablar con buen tono, y que son conocidos como los cachacos, el abolengo o la crema y nata de la sociedad. Se establece, entonces, una bifurcación nueva de sujetos: la de los salvajes insensibles y la de los sensibles y de tacto, en el sentido que aquí hemos expuesto.

\section{Discusión: El siglo XX y el caso de los cachacos y los corponchos}

En 1928, la ciudad de Bogotá tenía un poco más de doscientos treinta y cinco mil habitantes. Estaba gobernada por un atomismo social donde unos vivían en el sueño de sus mundos privados y otros, despiertos, luchaban por sobrevivir. Pero eso sí, todos seguían utopías personales desvaídas gracias a la naciente multitud, como sucede en la modernización urbana general (Bucks-Morss, 2004). Se sabe que el aspecto físico de la ciudad tomó un rostro cada menos aldeano (Zambrano, 2007), pero siguió reproduciendo una lógica social colonial que se defendía como esquema social único. Este fue un mecanismo de la élite para seguir con sus beneficios materiales y morales, tal como aparece en algunas descripciones de la época:

Bogotá es un pueblo grande, ensimismado, frío, con la tristeza del páramo ochos meses al año y sólo [sic] tres de sol y cielos despejados, donde la gente parece vestir siempre de luto. En invierno llueve a toda hora y las calles se convierten en lodazales donde se hunden los coches de caballos. En verano hay polvo en todas partes y cunden las pulgas, moscas, piojos y ratones [...]. La gente decente se precia aún de sus pasados españoles y copia los modales de París y Londres. Pero debajo de ese 
barniz hay mucha malicia, envidia e hipocresía, y todo el mundo vive pendiente del qué dirán. (Zalamea, 1993, p. 7)

En efecto, la ciudad de Bogotá de comienzos del siglo XX resulta ser un buen ejemplo de metrópoli donde el elitismo discriminó los cuerpos desiguales y los siguió segregando. Para la élite bogotana, todos eran iguales, pero había unos más iguales que otros. Esta empresa social fue auspiciada por un discurso jalonado por la empatía de médicos y pedagogos (Noguera, 2003), pero también de abogados, políticos, eclesiásticos, ingenieros y reformadores de la ciudad. En conjunto, todos ellos dinamizaron en el siglo XX debates sobre la raza y sobre las reformas sanitarias en que debía avanzar la cada vez menos aldea colonial. De esta manera, no solo redujeron al excluido como un condenado por su condición genética y climática, sino como un obstáculo para el avance de la nación. Todo esto se hizo bajo un embrujo modernizante de unos pocos que desearon apocadamente adaptar los cuerpos de los muchos a sus nichos. Tal como afirma el filósofo y profesor Juan José Lozano (2001):

La élite política y social bogotana, con sus deseos progresistas y ánimo reformista, encontró en el pueblo colombiano y bogotano una raza enferma y una mano de obra deficiente. Para ella, el pueblo fue sinónimo del conjunto de personas vulgares, incultas, insalubres, desnutridas y enviciadas que necesitaba ser transformado con él ánimo de hacer progresar el país. Pronto, como es de costumbre con lo marginado y exótico, se convirtió en objeto de intervenciones sociales, teóricas y científicas, pasando por las campañas contra el alcoholismo, a favor de la higiene y la reubicación de sus habitaciones, hasta grandes controversias sobre la raza colombiana que dejaba al pueblo como un montón de perezosos. (2001, p. 84)

Hacia 1920 se impone, entonces, la idea que los cuerpos de los segregados pueden ser maleables gracias a unas acciones educativas como parte de un plan cuya meta era el progreso urbano y el fortalecimiento moral. No obstante, tal obsesión resultó ser una quimera, pues las diferencias sociales entre élite y pueblo se interpuso sobre esa noble causa transformativa. En efecto, los manuales de urbanidad moderna y los deseos de refinamiento conductual solo fueron visibles y efectivos entre un mismo grupo, el de los favorecidos. En este sentido, como alerta el historiador francés Jacques Revel (1989), las normas que regulaban esos buenos modales y esas sensaciones distinguidas se propagaron, pero no para que todos los moradores de las ciudades las pusieran en práctica, sino para que fueran patrones de reconocimiento y privilegio para solo una capa social. Esto quiere decir que operaban bajo la lógica de presencia/ausencia.

En nuestro caso, la presencia de las buenas costumbres evidenciaba la idea de ser de la alta cultura bogotana, lo que coincidió, desde entonces hasta la actualidad, con ser la clase dirigente del país. Esta se caracteriza por tres rasgos esenciales: i) su constante pulsión por apartarse de lo popular; ii) su 
tradición hispano-católica y racionalidad económica como garante para interpretar el mundo; y, finalmente, iii) sus constantes nexos con países europeos. Por esta razón, se cultivan como sujetos cosmopolitas, plurilingües y peregrinos constantes hacia los países de Europa y hacia Estados Unidos. Así pues, en el espacio urbano de la Bogotá del siglo XX, se acoplaron las diferencias que fueron fundamentalmente urbanas, morales y estéticas.

Este conjunto de fisonomías cultivadas en las capas sociales de linaje moderno fue la premisa de un orden social que adquirió un renovado rostro con dos aristas enfrentadas: por un lado, los cachacos cosmopolitas en sus casas y teatros de estilo francés o inglés; por otro lado, el pueblo abigarrado entre viviendas populares, estrechas y desaseadas. Estas aristas también fueron leídas desde una cartografía que determinó cierta taxonomía excluyente: la de los cachacos, civilizados y superiores, representantes de la zona andina o de las tierras frías; y la de los corronchos, bárbaros, salvajes y haraganes, habitantes de las costas. Esto quiere decir que se combinó exitosamente la herencia de la sociedad republicana que, a la idea de castas sociales, sumó tipos humanos o pueblos diferenciados por temperamentos, costumbres y conductas asociadas a ciertas características del cuerpo humano, el clima y la región, tal como lo defendieron en el siglo XIX Francisco José de Caldas (Arias, 2007) o José María Samper (Villegas, 2008). Es así como se puso en marcha esta concepción y, sustentada por referentes socioculturales, ecológicos y climáticos, terminó estimando "grados de civilización" en los sujetos y los colectivos en Colombia (Taussig, 1987).

Dentro de este marco, la Bogotá del siglo XX comenzó a ser suelo fértil para evidenciar, por una parte, la herencia colonial que dejó el fantasma de una esencia de nobleza escenificada en modales y costumbres. Por otra parte, se reveló una clasificación poblacional y una orientación identitaria mediada por la relación raza-territorio (Pedraza, 2008). En otras palabras, se creó una nueva segregación social basada en la heterogeneidad geográfica y racial. Desde hace más de dos décadas, el antropólogo británico Peter Wade (1997) afirmó que la formación del Estado colombiano ha estado guiada, desde el siglo XIX, por la promesa de una geografía que racializa las regiones, lo que permite pensar en una primacía de lo andino en la construcción social de la nación, a la cual se le

Así, por ejemplo, los conquistadores españoles calificaron a los indios a partir de su similitud con ellos mismos. A partir de ese criterio, los grupos andinos con organización estatal fueron definidos como bárbaros, pero parecidos a ellos gracias a sus formas de organización cultural y económica. Por otro lado, los grupos andinos que no tenían sociedades Estado fueron calificados de bárbaros, desgraciados y pobres por no poseer oro. Asimismo, la selva amazónica (con sus animales y hostilidades medioambientales) era el averno, con lo cual sus moradores no pasaron de ser unos salvajes. De allí surge ese imaginario de indio caníbal, cruel y amoral por estar desnudo y hacer el amor en la selva. 
asigna un alto grado de moralidad, prelación céntrica y capacidad de progreso socioeconómico.

Se instaló, entonces, entre las élites andinas autoclasificadas como raza blanca, el miedo a perder sus cualidades nobles y debilitarse al asimilar todo lo que estaba apiñado en las tierras costeras, tal como había ocurrido, por ejemplo, con las clases dirigentes en Panamá que terminaron disipando sus peculiaridades de cuna al convivir con mulatos y negros en las tierras bajas y ardientes de ese territorio (Múnera, 2005). Esto justifica que el habitante de las costas colombianas fuera el otro opuesto. El mote de corroncho simplifica todos esos valores negativos que, por instalarse en el clima cálido de la región costera, justifica su segregación, con altos grados de naturalización hasta el día de hoy, en la imaginada nación colombiana. Esto se comprueba fácilmente cuando aún se confirma que

lo caribe está muy asociado a los escándalos de corrupción política, a los casos de paramilitarismo y parapolítica, a los índices notables de pobreza, miseria, prostitución y trabajo infantil [al tiempo que] tenemos la idea de lo sabroso, lo erótico, el desparpajo, la alegría, en general, el cogerla suave con los que se asocia a los costeños en Colombia. Es así como la idea de lo exótico y la periferia se mantiene, así sea con un matiz mucho más tenue que antes, en la representación de estos personajes y de lo costeño en general, está implícito esa esencia tan particular que se le atribuye al ser caribe. (Argel, 2008, p. 142)

Es así como corroncho, neologismo surgido de la contracción de la expresión "con la roncha" - referida a las cicatrices visibles en la piel que producen las picaduras de insectos en el hombre del caribe hispano y que alude primariamente a un campesino ladino y genuino del Caribe colombiano- ha pasado a significar, por obra de las producciones y divisiones sociales en Colombia, el hombre nativo de la región montuna-caribe de Colombia sin importar el color de su piel (Contreras y Álvarez, 2012). Es muy similar al sentido peyorativo de lobo en la zona andina colombiana ${ }^{7}$, el cual se asocia con una gastronomía, un dialecto y una música popular muy locales, representado habitualmente en el porro, el vallenato o la cumbia y sus respectivas danzas.

Desde la mirada de los cachacos a comienzos del siglo XX, este tipo de música asociada a los corronchos o corronchonchones, era entendida como la expresión de un baile desaforado y lleno de convulsiones cuasi epilépticas (Múnera, 2002). Por esta razón, esta música fue interpretada como una melodía del Caribe salvaje colombiano, esto es, un discurso ávido de errores del habla y, por tanto, flagrantemente menospreciado. Quizá por esto mismo, la música

En efecto, aún se considera que el corroncho es la versión mulata de un lobo bogotano, aunque, efectivamente, se pueden establecer diferencias culturales fundamentales que tiene que ver con las cosmovisiones rurales y urbanas esnobistas y con esa pulsión a imitar modas y objetos de estilo inglés o francés. 
vallenata solo comenzó a escucharse a finales de la década de 1960 en Bogotá. Así era el talante de la injusticia epistémica frente a este tipo de manifestaciones artísticas caribeñas, lo que también afecta la imagen del hombre campesino de regiones calurosas y agrarias desde la Colonia hasta nuestros días.

De manera tímida pero efectiva, esta esta división sociorregional y climática ha persistido y se ha naturalizado en todos los escenarios sociales de las últimas décadas. La evidencia de ello es que esta segregación fue revivida en el cierre del evento con la exhortación "iPor favor, sea corroncho!", que clausuró el evento Hay Festival en la ciudad de Cartagena de Indias en enero de 2018 (Díaz, 2018; Mejía, 2018). Daniel Samper Pizano y Juan Gossaín, los periodistas y miembros de la Academia Colombiana de la Lengua (el primero cachaco, el segundo corroncho), junto con Hernán Villa, conocido como el Corroncho Villa y autor del porro $\mathrm{El}$ corroncho, dialogaron sobre el mote corroncho y su historia. Efectivamente, estos periodistas confirman que el término tomó el matiz pragmático despectivo o peyorativo con el sentido de costeño burdo y de mal gusto, el cual fue generalizado desde la ciudad de Bogotá para referirse a los moradores del Caribe y, por extensión, para cualificar a personas sin cultura y sin modales. Lo interesante es que, lejos de ser un tema académico, este sistema de ordenamiento social sirvió para que el mismo Gossaín valorara las controversias generadas a propósito de la delegación que llevaría el escritor costeño Gabriel García Márquez a la ceremonia de recepción del Nobel de Literatura en Estocolmo (Suecia), el 10 de diciembre de 1982 y, más exactamente, al banquete de celebración.

Efectivamente, varios protagonistas del abolengo céntrico del país -el embajador de Colombia en Suecia y algunos periodistas bogotanos- hicieron fuertes críticas, cuando se enteraron de que sesenta y cinco artistas de varias regiones del país acompañarían García Márquez en Estocolmo, sobre el ridículo que se haría en Suecia. Tacharon abiertamente de corronchada el deseo de Gabo de celebrar su premio con cumbias y vallenatos, tal como lo confesó él mismo al periodista Germán Santamaría, reportero del diario El Tiempo, tras conocerse la noticia el 21 de octubre de $1884\left(\right.$ Ferez, 2018) ${ }^{8}$. De hecho, tras saberse que García Márquez iría con esta delegación vernácula (algunos desdentados y sin haber obtenido nunca su pasaporte) y que el escritor cataqueño iría vestido de

Entre esos sesenta y cinco artistas, viajaron Rafael Escalona, las cantantes Leonor González Mina, "la negra grande de Colombia", y Totó la Momposina. Además, fue el grupo vallenato Los Hermanos Zuleta (Poncho y Emiliano). Fueron bailarinas de cumbia barranquilleras, grupos de danza del Atlántico y de la región llanera; incluso la misma Consuelo Araújo Noguera, la Cacica, promotora cultural de la época, actuó como una bailarina más. En abril de 2017 se filmó el documental Cuando Colombia se volvió Macondo, coproducción de Señal Colombia y el Ministerio de Cultura, donde Gloria Triana, directora de Colcultura en 1984 (hoy Ministerio de Cultura en Colombia) reconstruye, en calidad de directora del documental, todos los momentos con sus protagonistas vivos. 
blanco con el traje tradicional llanero llamado liquiliqui, sugirieron que se dejara el carnaval para los colombianos, pero no para los suecos:

[El periodista bogotano] Roberto García-Peña, D’Artagnán, calificó a la delegación de frívola y tituló que Colombia haría "un acto de lesa lobería" en Estocolmo. La locura de llevar noventa personas a la entrega del Nobel, cuando la organización solo le permitía llevar un pequeño grupo, se le debe a dos personas: al presidente Belisario Betancur, y a la ministra Aura Lucía Mera, quien fue donde Santo Domingo, gerente de Avianca, y dijo: "Necesito que me presten un jumbo para llevar toda la delegación". "Soy lobo de provincia", dijo sonriente Belisario, al evocar aquellos días, entrevistado por Gloria. Y le dijo a D'Artagnán que "ser lobo es parte de mi biografía. Lobo Betancur". (Tatis, 2018)

La defensa del presidente fue entendida rápidamente, puesto que él mismo no era de la crema y nata de la élite bogotana, sino que procedía de un pueblo antioqueño que, en la actualidad, no supera los treinta mil habitantes. Aunque se recuerda paradójicamente, él mismo pidió que le mostraran las coreografías en un teatro bogotano antes del viaje a Estocolmo. Tras todos estos rifirrafes que evidenciaron hace treinta y siete años la tensión social entre cachacos y corronchos, sabemos que el evento folclórico fue bien recibido por los suecos. La idea del escritor cataquero terminó en un acto donde, por un momento, se universalizó la música popular corroncha en un circuito ceremonial tan solemne como el sucedido en el ayuntamiento de Estocolmo. Así pues, tras saberse de la emoción de los reyes de Suecia al escuchar los ritmos corronchos y del éxito general de la delegación tropical, expertos en protocolos y periodistas de Bogotá se vieron forzados a retractarse y reconocer el acierto.

A partir de esto, cabe sostener cómo esas divisiones sociales, con esa repetición que viene calcada desde la Colonia bajo los motes de la República de hidalgos-república de indios, no son más que efectos de segregación que se siguen colando en el idiolecto usado en una ciudad como la actual Bogotá, donde hay cachacos, lobos, corronchos, sumado a rolos, bogotanos y bogoteños. Estos gentilicios y apodos cargan en sus entrañas semánticas despectivas de una esencia del ser bogotano, cada vez más quebrantada por las constantes migraciones, pero que siguen recordando esa tajante segregación racial-regional (Ospina, 2006) que perennemente resalta la primacía de lo andino sobre otras regiones. De hecho, así lo confirma el propio García Márquez en su novela autobiográfica cuando a firma que "Colombia fue desde siempre un país de identidad caribe abierto al mundo por el cordón umbilical de Panamá; pero la amputación forzosa nos condenó a ser lo que hoy somos: un país de mentalidad andina" (García Márquez, 2002, p. 538).

El cachaco, como representante exclusivo de la región andina y esa mentalidad excluyente y odiosa, sigue denotando hasta el día de hoy la imagen de un 
ciudadano de raigambre y abolengo comprobados: bien vestido, bien hablado, elegante y con buenos modales. El rolo es el hijo de un padre bogotano y otro de afuera, esto es, un criollo nacido en Bogotá, cuya característica es arrastrar el fonema vibrante alveolar /rr/ (del anglicismo roll). El bogotano es el hijo nacido en Bogotá, pero de padres no bogotanos. Por último, el bogoteño es oriundo de una ciudad diferente a Bogotá, pero ha vivido al menos una década en la capital colombiana.

De esta manera, se nota que la primacía del cachaco no se da solo sobre el corroncho, sino también sobre los que no demuestren ser de cuna noble bogotana, que es el sentido profundo de referir diferencias entre cachacos, rolos, bogotanos y bogoteños. El caso de rolo es una enunciación con una clara función peyorativa, pues a comienzos del siglo XX se usaba para que los cachacos y su estirpe nombrara a los indios y a los mestizos que habitaban en las sabanas de la ciudad de Bogotá (Restrepo, 1995).

No obstante, lo paradójico de esto es que el apodo cachaco no siempre ha referido esa noble capa social superior amañada en los lugares acreditados de la ciudad capital. En el siglo XVII, la palabra cachaco era un adjetivo tan despectivo como hoy lo es lobo o corroncho, ya que calificaba a los jóvenes deslucidos o mal vestidos. Fue en el siglo XIX cuando tomó la función gramatical de sustantivo para referir a un joven de orientación política liberal, tal como confirma el dialectólogo Cuervo (2012). Efectivamente, muchos jóvenes mal vestidos que lucharon en las batallas bipartidistas del país hacia 1830 eran liberales, grupo político que a la postre salió vencedor tras las confrontaciones con los guerreros de orientación conservadora. De suerte que este concepto, al cambiar de sentido, pasó a denotar elegancia en la forma de vestir y buenas maneras en las interacciones públicas y en las finas conductas privadas de su hogar. Este sentido se reforzó con el sentido asociado a la castellanización del del galicismo cachet coat, tradicionalmente coligado desde finales del siglo XIX con los cachacos, que alude a una gabardina o casaca típicamente usada por el abolengo bogotano para protegerse de las lloviznas y el frío típico de la cordillera.

\section{A manera de colofón}

Llegados a este punto de reflexión, creemos que esta forma de afrontar y construir cuerpos humanos, propios y ajenos, y luego inscribirlos en ciertos lugares, ora de prestigio, ora de segregación dentro de los cuerpos urbanos, se asocia con lo que el lingüista búlgaro Todorov (1987) propone para enfrentar el tema de la pugna entre desiguales. Esta propuesta abrevia en la intersección de tres planos: un plano axiológico, donde el otro es bueno o malo, se quiere o no, es igual o es inferior; un plano praxeológico en el que se evidencia la acción de 
acercamiento o alejamiento en relación con el otro al adoptar sus valores o al querer asimilar al otro a la imagen propia; y el plano epistémico, donde se sabe o se ignora la identidad del otro y se presenta una gradación infinita entre los estados de conocimiento. Este último plano guarda relación con lo que la poscolonialista india Gayatri Spivak (2012) llama violencia epistémica. Este tipo de violencia se ejerce sobre el que se considera inferior (indio, costero, mestizo) y, por eso mismo, se hace una fetichización de lo europeo. De esta manera, se creando entre todos nosotros lo que, en 1932, el filósofo colombiano Fernando González (2014) denominó complejo de inferioridad o de ilegitimidad.

Aún más, esta propuesta se complementa con la de Gerd Baumann quien, al intentar responderse cómo se edifican las alteridades, propone una compleja gramática de la alteridad. Esta es la propuesta más radical en los ambientes occidentales, la orientalista o de inversión, que recuerda la simpleza de las oposiciones nosotros versus ellos, pero explotadas hasta su máximo contraste. Al respecto, Baumann (2001) afirma:

La gramática del orientalismo no se limita a 'esto es nuestro, y es bueno; y esto es suyo, y es malo' [...] es también una astuta inversión reflejada: 'lo que es bueno en nosotros es malo en ellos, pero lo que está torcido en nosotros permanece derecho en ellos' [...]. [L]a versión xenófoba consiste en buscar la superioridad, sean cuales sean los méritos que uno considere propios, la xenófila está en buscar la redención de ese Otro que es tanto reflejo nuestro como de sí mismo. (p. 55)

Si bien es cierto que existen relaciones y afinidades entre los tres planos todorovianos y sus gramáticas constitutivas, también es incuestionable que no hay implicación rigurosa. No obstante, desde la perspectiva del superiorcachaco hacia el otro-diferente aparecen narrativas cotidianas donde el corroncho posee valores negativos (malintencionado, perezoso, timadores, lascivo en exceso, etc.), lo cual produce un alejamiento con su desasimilación que se funda en un desconocimiento de su realidad. Este hecho mueve a una de las partes comprometidas en la interacción, al intentar excluir a través de un temor que le permite alejarse, o bien asimilar a través de una violencia simbólica como último recurso. Pero la escisión social entre los sujetos diferentes puede tener otras vías de comprensión si se piensa que, frente a la posibilidad de la interacción, se impone la versión de una de las dos caras, dependiendo del punto de vista desde donde se vea la cuestión. Es por esto por lo que, desde la perspectiva del corroncho, hay también un rencor hacia el cachaco.

Se asiste, entonces, a una gramática del reflejo o la inversión recíproca. Este hecho evidencia que el lazo entre diferentes no puede hacerse por vía implícita de un pacto simbólico porque de entrada no se pone algo común, sino que algo se impone desde el estereotipo cifrado en cachaco o corroncho, con el consecuente opacamiento o asimilación del otro y su inmediata carga axiológica de negativi- 
dad. En este contexto, la situación interactiva entre unos y otros suele devenir en una violencia contra el vínculo social establecido y solo queda la imposición o la rebelión en una labor que ignora límites. No obstante, queda una terrible realidad paradójica: el otro es un sujeto "diferente" que vive entre nos-otro-s (lo cual lo hace inmediatamente malo, inferior e indigno de conocer) y ya no basta el atrincheramiento espacial urbano. Aparece, entonces, por un lado, el odio como mecanismo para romper el lazo con ese otro, para eliminarlo. Por otro lado, aparecen ciertas aversiones o rechazos que se evidencian especialmente por la multiplicación de zonas urbanas hiperdegradadas con dinámico flujo de inmigrantes, a saber: la aporofobia, la xenofobia y la mixofobia.

\section{Agradecimientos}

Gratitudes al Centro de Investigaciones y Desarrollo Científico (CIDC) de la Universidad Distrital, Francisco José de Caldas, pues este artículo de reflexión es producto de la investigación institucionalizada ante el CIDC con el código 2419167418.

\section{Referencias}

Amaya, B. (2016). Historias de Santafé y Bogotá. La Rueca.

Aprile-Gniset, J. (1991). La ciudad colombiana, prehispánica, de conquista e indiana. Banco Popular.

Argel, S. (2008). El sombrero vueltiao ¿Símbolo de Colombia? De lo corroncho y campeche a lo culto y de élite. Revista Aquelarre, 7(15), 139-154. http://ccultural.ut.edu.co/images/Revistas\%20Aquelarre/ Aquelarre\%2015.pdf

Arias, J. (2007). Seres, cuerpos y espíritus del clima. Pensamiento racial en la obra de Francisco José de Caldas. Revista de Estudios Sociales, (27), 16-30. https://doi.org/10.7440/res27.2007.01

Baudelaire, Ch. (2003). Obra poética completa. Akal.

Baumann, G. (2001). Tres gramáticas de la alteridad: Algunas antropo-lógicas de la construcción del otro en las constelaciones históricas. En M. Nash y D. Marre (eds.), Multiculturalismos y género: un estudio interdisciplinar (pp. 23-47). Ediciones Bellaterra.

Béjar, H. (1998). El ámbito íntimo. Privacidad, individualismo y modernidad. Alianza.

Bucks-Morss, S. (2004). Mundo soñado y catástrofe. Machado libros.

Calsamiglia, H. y Tusón, A. (2002). Las cosas del decir. Manual de análisis del discurso. Ariel lingüística.

Carreño, M. A. (2000). Manual de urbanidad y buenas maneras. Panamericana.

Contreras, N. y Álvarez, R. D. (2012). El corroncho o la dicotomía de los conceptos modernidad y autoctonía para un mundo en crisis de supervivencia. América Latina en Movimiento. https://www. alainet.org/es/active/53942

Cuervo, R.J. (2012). Apuntaciones críticas sobre el lenguaje bogotano. Instituto Caro y Cuervo. 
Díaz, G. (2018). "Por favor, sea corroncho", el mensaje de despedida del Hay Festival. El Universal. https://www.eluniversal.com.co/cultural/por-favor-sea-corroncho-el-mensaje-de-despedida-delhay-festival-271206-HCEU385471

Ferez, S. (2018). Amigos de Gabo revivieron la entrega del Nobel en Estocolmo. El Heraldo https://www.elheraldo.co/entretenimiento/amigos-de-gabo-revivieron-la-entrega-del-nobel-en-estocolmo-451748

Gaitán, E. (2005). Biografía de las palabras. Macroeditores.

García Márquez, G. (2002). Vivir para contarla. Norma.

González, F. (2014). Los negroides. Ensayo sobre la Gran Colombia. Fondo Editorial Universidad Eafit; Corporación Otraparte.

Gutiérrez, R. (1987). Modernismo. Supuestos históricos y culturales. Fondo de Cultura Económica.

Jaramillo, R. (1998). Colombia: la modernidad postergada. Argumentos.

Lozano, J. J. (2011). Cada cosa en su lugar. Políticas del espacio urbano, Bogotá 1918-1924. En D. Moreno (comp.), Comunicación, cultura y poder (pp. 81-94). Universidad Nacional de Colombia.

Marcuse, H. (1978). Acerca del carácter afirmativo de la cultura. En H. Marcuse (ed.), Cultura y Sociedad (pp. 5-66). Sur.

Mejía, É. (2018). Elogio al corroncho. El Punto. http://www.periodicoelpunto.com/elogio-al-corroncho/\#. X5X_gohKiM8

Mejía, G. (2011). En busca de la Intimidad (Bogotá, 1880-1910). En J. Borja y P. Rodríguez (eds.), Historia de la vida privada en Colombia. Tomo II (pp. 19-45). Taurus.

Múnera, A. (2002). El fracaso de la nación, región, clase y raza en el caribe colombiano. Banco de la Republica y Áncora editores.

Múnera, A. (2005). Fronteras imaginadas. La construcción de las razas y de la geografía en el siglo XIX colombiano. Planeta.

Noguera, A. (2003). Medicina y política: discurso médico y prácticas higiénicas durante la primera mitad del siglo $X X$. Eafit.

Ortiz, J.G. (2012). El buen bachiller: el debate del buen bachiller, 1940-1950, Revista Magistro, 12(6), 107-114.

Ospina, A. (2006). Rolo, cachaco, bogotano: ¿más que inocentes palabras? El Blogotazo. http://blogs. eltiempo.com/el-blogotazo/2006/09/22/rolo-cachaco-bogotano-mas-que-inocentes-palabras/

Páramo, P. (2002). En busca de la identidad del bogotano: interacción con el pasado de la ciudad en el espacio público. Territorios, 8, 63-84. https://revistas.urosario.edu.co/index.php/territorios/ article/view/5684

Pedraza, Z. (1999). Las hiperestesias: principio del cuerpo moderno y fundamento de diferenciación social. En M. Viveros y G. Garay (comps.), Cuerpo, diferencia y desigualdades (pp. 42-53). Facultad de Ciencias Humanas.

Pedraza, Z. (2004a). Intervenciones estéticas del yo. Sobre estético-política, subjetividad y corporalidad. En M. C. Laverde, G. Daza y M. Zuleta (eds.) Debates sobre el sujeto. Perspectivas contemporáneas (pp. 61-72). Siglo del hombre editores. 
Pedraza, Z. (2004b). Y el verbo se hizo carne... Pensamiento social y biopolítica en Colombia En S. Castro-Gómez (ed.), Pensar el siglo XIX. Cultura, biopolítica y modernidad en Colombia (pp. 185199). Universidad de Pittsburgh.

Pedraza, Z. (2008). Nociones de raza y modelos del cuerpo. Revista Aquelarre, (15), 41-59. http://ccultural. ut.edu.co/images/Revistas\%20Aquelarre/Aquelarre\%2015.pdf

Pedraza, Z. (2011). La educación del cuerpo y la vida privada. En J. Borja y P. Rodríguez (eds.), Historia de la vida privada en Colombia. Tomo II (pp. 115-150). Taurus.

Rama, Á. (1984). La ciudad letrada. Hanover.

Romero, J.L. (1974). Latinoamérica: las ciudades y las ideas. Siglo XXI Editores.

Restrepo, R. (1955). Apuntaciones idiomáticas y correcciones del lenguaje. Imprenta Nacional.

Revel, J. (1989). Los usos de la civilidad. En P. Aries y G. Duby (eds.). Historia de la vida privada III (pp. 169-209). Taurus.

Silva, J. A. (1993). De sobremesa. El Áncora Editores.

Simmel, G. (1986). Las grandes urbes y la vida del espíritu. En G. Simmel (ed.), El individuo y la libertad. Ensayos de crítica de la cultura (pp. 247-261). Península.

Spivak, G. (1985/2012). ¿Puede hablar el subalterno? Revista Colombiana de Antropología, (39), 257-364. https://www.redalyc.org/pdf/1050/105018181010.pdf

Tatis, G. (2018). Gloria Triana, Memoria del Nobel en Estocolmo. El Universal. https://www.eluniversal. com.co/suplementos/facetas/gloria-triana-memoria-del-nobel-en-estocolmo-279916-NBEU395796

Taussig, M. (1987). Shamanism, colonialism and the wild man. A study in terror and healing. The University of Chicago Press.

Todorov, T. (1987) La conquista de América. El problema del otro. Siglo.

Villegas, Á. (2008). Heterologías y nación: proyectos letrados y alteridad radical en la Colombia decimonónica. Signo y Pensamiento, 27(53), · 25-37. https://revistas.javeriana.edu.co/index.php/ signoypensamiento/article/view/4553

Wade, P. (1997). Gente negra, nación mestiza. Dinámicas de las identidades raciales en Colombia. Siglo del Hombre Editores.

Zalamea, L. (1993). Las guerras de la champaña. Tercer Mundo Editores.

Zambrano, F. (2007). Historia de Bogotá: siglo XX. Villegas Editores. 